\title{
Motor Learning and Virtual Reality in Down Syndrome; a Literature Review

\begin{abstract}
Lilian Del Ciello de Menezes ${ }^{1}$, Thais Massetti ${ }^{1,3}$, Fernando Rocha Oliveira 2,4, Luiz Carlos de Abreu ${ }^{3,4}$, Dafne Herrero 3,4, Silvia Regina Pinheiro Malheiros ${ }^{3}$, Isabela Lopes Trevizan ${ }^{1,3}$, Cristina Hamamura Moriyama ${ }^{3,4}$, Carlos Bandeira de Mello Monteiro ${ }^{1}$
\end{abstract}

\section{Abstract}

Down syndrome (DS) is caused by trisomy of human chromosome 21 (Hsa21) and results in a large number of phenotypes including learning difficulties, cardiac defects and distinguishing facial features. The purpose of this study was to analyse research findings about "motor learning" and "virtual reality" in patients with DS. Relevant studies were identified by searching PubMed, Web of Science and BVS (virtual library in health). Using key words, we searched for articles that included Down syndrome, virtual reality, and motor learning. Only studies on humans were eligible. The search identified seven relevant papers. Most studies showed that individuals with Down syndrome are able to learn new tasks, and that improvements can be enhanced via the use of virtual reality. We conclude that individuals with Down syndrome respond positively and effectively, with improvements in sensory motor control, when stimulated with tasks that are complementary to conventional therapy, including therapy involving virtual reality.

\section{Keywords}

Down Syndrome, Virtual Reality, Motor Learning.
1 Programa de Pós-graduação em Ciências da Reabilitação. Faculdade de Medicina da Universidade de São Paulo, SP, Brasil.

2 Programa de Pós-graduação em Cardiologia. Universidade Federal de São Paulo, SP, Brasil.

3 Laboratório de Delineamento de Estudos e Escrita Científica. Departamento de Saúde da Coletividade. Disciplina de Metodologia Científica. Faculdade de Medicina do ABC. Santo André, SP. Brasil.

4 Programa de Pós-graduação em Epidemiologia. Faculdade de Saúde Pública da Universidade de São Paulo, SP. Brasil.

\section{Contact information:}

\section{Lilian Del Ciello de Menezes.}

Programa de Pós-graduação em Ciências da Reabilitação da Faculdade de Medicina.

Address: Universidade de São Paulo, Rua: Cipotânea, 51. Cidade Universitária, São Paulo, SP, Brasil.

Đ liliandelciello@usp.br

\section{Introduction}

Down syndrome (DS) is caused by trisomy of human chromosome 21 (Hsa21) and results in a large number of phenotypes including learning difficulties, cardiac defects and distinguishing facial features [1]. The syndrome is associated with approximately $1 / 800$ live births and is one of the leading causes of intellectual disabilities [2]. 
In general, the movements of individuals with Down syndrome can be described as "clumsy," the characteristics of which are slowness and low efficacy [3]. Palasiano et al. [4] reported that gross motor function improves in children with Down syndrome as they grow, and that they require more time to learn movements as movement complexity increases. Lott and Dierssen [5] reported that all individuals with DS exhibit some form of learning and memory impairment, which varies in severity.

Considering that skilled movements are fundamental to human experience, an analysis of how motor learning (ML) can be optimized in people with DS does not have only theoretical interest, but also important practical implications for the lives of these people [6]. According to Maas et al. [7], motor learning refers to a set of processes associated with practice and experience leading to relatively permanent changes in performance, arising from systematic practice and feedback.

There are some authors studying the motor learning area in DS like, Chiviacowsky et al. $[6,8]$ that showed the effect of knowledge of frequencies on motor learning in adults with DS; Bussy et al. [9] compared the perceptual learning of individuals with Fragile $X$ and DS; Possebom et al. [10] studied motor learning in this population with the help of a maze task on the computer, and Ringenbarch et al. [11] attempted to understand how people with DS perform the different tasks of continuous drumming and unimanual drumming. This is a new approach and has been many used, and this seems to be very interesting considering the advances in technology and also being an instrument that can make feasible tasks in computing environments. With the advancement of technology, and its various possibilities, the use of virtual reality is becoming more widespread in several areas, and showing considerable growth in the area of motor learning.

Traditional therapies for movement difficulties in children with disabilities are repetitive and offer very little to keep a young person interested [12]. Virtual reality (VR) provides a unique medium suited to the achievement of effective rehabilitation intervention. Specifically, therapy can be provided within a functional, purposeful and motivating context [13]. The ability to change the virtual environment relatively easily, to grade task difficulty and to adapt it according to the patient's capabilities are important advantages of VR, since these features are essential to cognitive and motor remediation [14].

Cognitive and motor difficulties in DS have been reviewed by several authors. Adamovich et al. [12] reviewed the documented adverse events occurring following participation in physical activity among individuals with psychological or cognitive conditions. Relevant studies were identified through electronic database searching. Populations with dementia, psychological disorders, or intellectual disability do not report considerable or consequential adverse events following physical activity independent of associated comorbidities. The one exception to these findings may be Down syndrome populations with atlantoaxial instability. However, their review highlighted the relative paucity of the reported presence or absence of adverse events, and found that many studies are at high risk of bias toward reporting naturally occurring adverse events.

Damiano and Dejong [15] reviewed the effectiveness of treadmill training and body weight support in paediatric rehabilitation. A systematic review was undertaken to explore the strength, quality, and conclusiveness of evidence supporting use of treadmill training and body weight support in those with paediatric motor disabilities, including DS. They found that the efficacy of treadmill training in accelerating walking development in DS has been well documented. However, further randomized studies, studies with treadmill trainingonly groups, and dosage studies are needed before practice guidelines can be formulated. Neural 
changes in response to training warrant exploration, especially given the capacity for change in developing nervous systems.

Besides these research review about DS, virtual reality technology may be an optimal tool for designing therapies that target neuroplastic mechanisms in the nervous system, may manipulate the specificity and frequency of visual and auditory feedback, and provide adaptive learning algorithms and graded rehabilitation activities that can be objectively and systematically manipulated to create individualized motor learning paradigms [12]. While virtual reality (VR) is a recently emerging form of rehabilitation therapy, this novel treatment approach has exciting implications for neurocognitive rehabilitation but little has been done to review the studies applying VR to the rehabilitation of children [16] and motor learning.

The purpose of this study was to analyse research findings about "virtual reality" in persons with "Down syndrome" and the instruments used to verify "motor learning" in persons with "Down syndrome". Specifically, we wanted to determine which methods are being used to infer motor learning in this population, and when using virtual reality, what are the main outcomes.

\section{Method}

A literature search was Performed using PubMed, Web of Science and BVS (virtual library in health). Using keywords, searched for articles included the terms Down syndrome, virtual reality, and learning engine. The Review of work included only Conducted from 1994 to 2014 and human species

To select the articles three steps were used. The first step involved searching for articles in the databases, reading the titles and abstracts; the second step involved the exclusion of works by title or abstract, and exclusion by our inclusion criteria; the third and final step involved analyzing the eligible studies.

Figure 1: Database search.

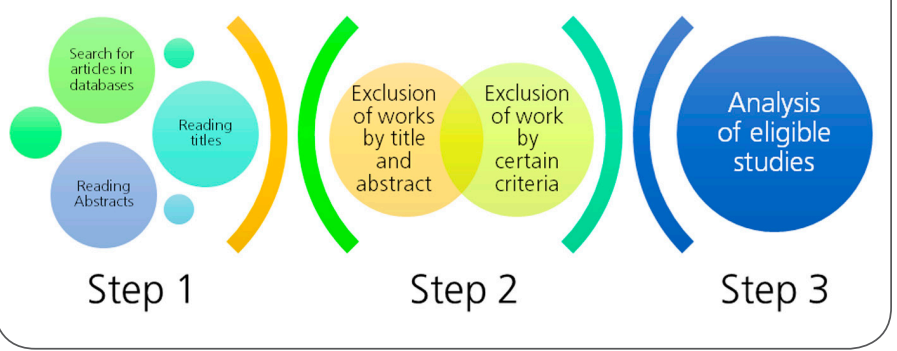

In the same way as Snider, Majnemer and Darsaklis [17], we used a search strategy based on PICOs the PICOs it can be defined by P: Patient; I: intervention, C: comparison; O: Outcomes; S: studys, used to locate and compare different studies.

Figure 2: Representation of the search strategy - PICOs $-\mathrm{DS}+\mathrm{ML}$ and DS +VR.

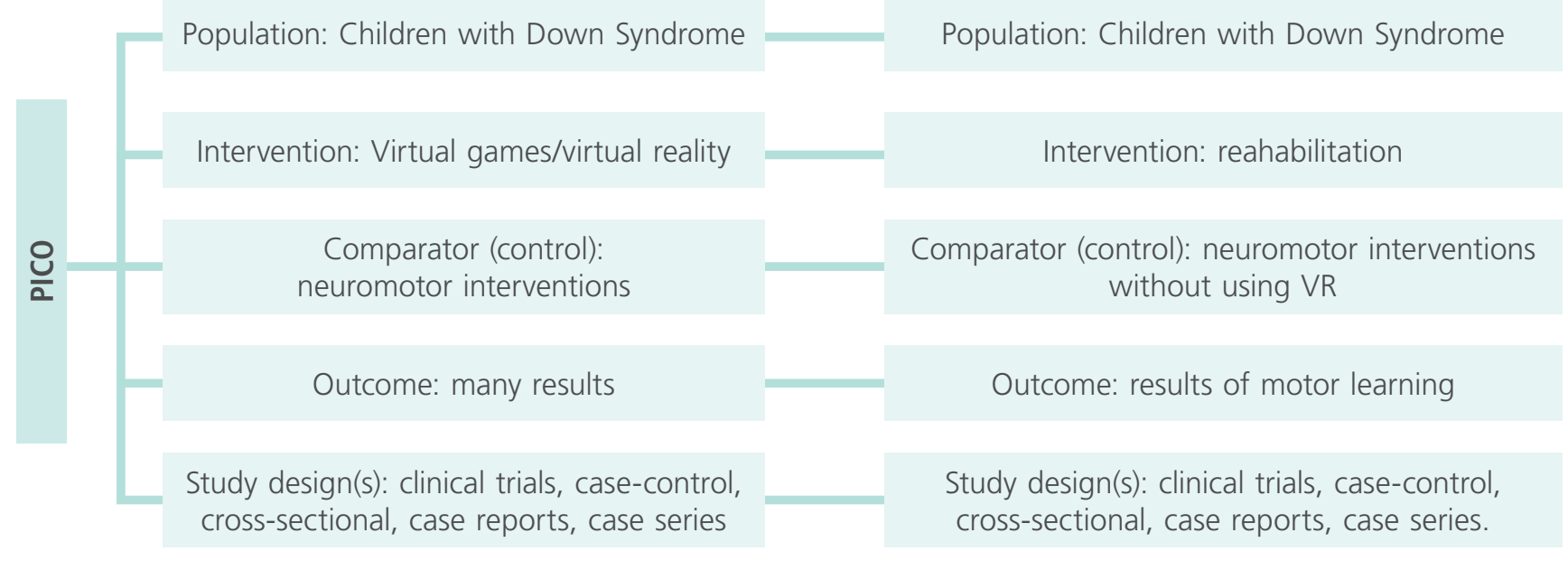


To increase confidence in the selection of articles, all potentially relevant articles were reviewed independently by two researchers, who after reading through all of them, reached a consensus to establish which articles fulfilled the inclusion criteria [18].

There are many available scales to help evaluate study quality, the most commonly used in the rehabilitation area being the PEDro scale [19]. This scale was developed by the Physiotherapy Evidence Database to be used in experimental studies and has a total score of 10 points, including evaluation criteria of internal validity and statistical analysis used [19].

In order to demonstrate the methodological quality of the studies, an article with a good level of evidence was considered to be one with a score equal to or higher than 6 according to the PEDro evaluation scale. This criterion was based on Snider, Majnemer and Darsaklis [17], who considered studies scoring 9-10 on the PEDro scale to be methodologically 'Excellent', 6-8 'Good', 4-5 'Fair' and below 4 'Poor'.

\section{Results}

The search of PubMed Medicine ${ }^{\circledR}$, Web of science and BVS (virtual library in health) identified 194 studies, 187 of which did not fit the inclusion criteria. The data extracted from the seven eligible studies is summarized in Figure 3.

Figure 3: Flow diagram of the article selection process

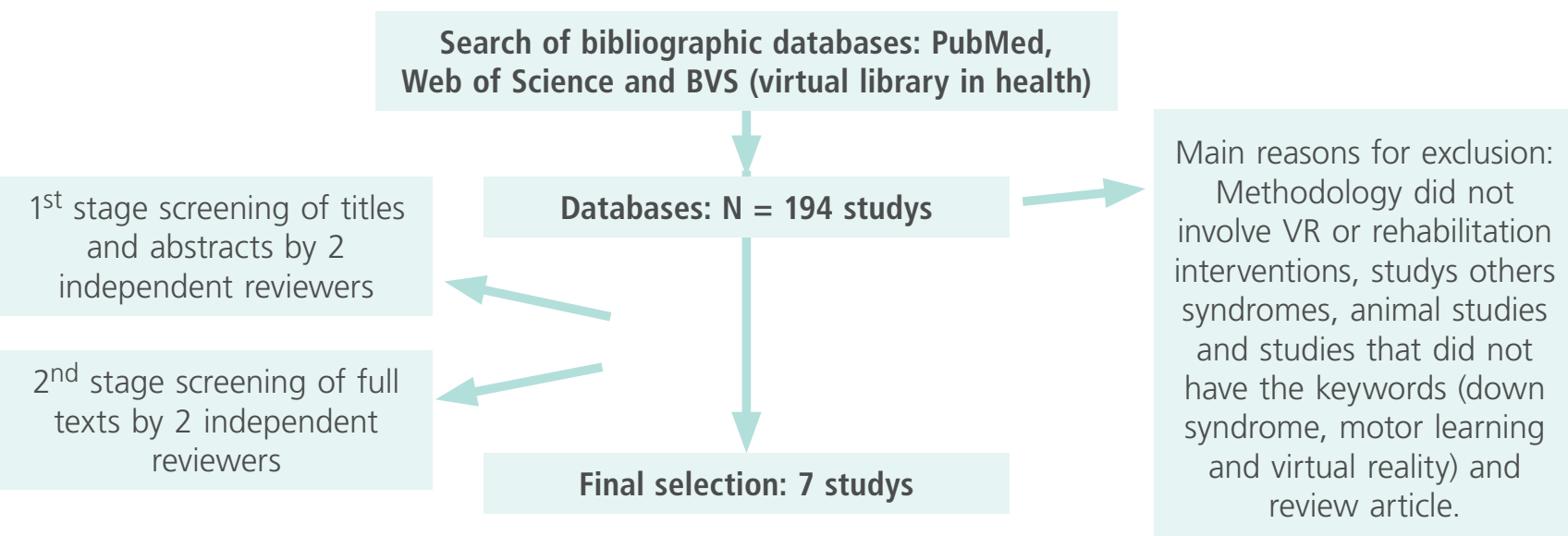

Table 1. Outline methodology of the studies analysed.

\begin{tabular}{|c|c|c|}
\hline Study reference & Nature & Frequency and duration \\
\hline Wuang et al., 2011 & RCT & $\begin{array}{l}\text { The study was conducted during 2009-2010. Each intervention group received a } 1 \mathrm{~h} \\
\text { session } 2 \text { days per week for } 24 \text { weeks. }\end{array}$ \\
\hline Bussy et al., 2011 & RCT & One session of approximately $30 \mathrm{~min}$. \\
\hline Chiviacowsky et al., 2012 & $\mathrm{RI}$ & $\begin{array}{l}\text { A task in which all participants performed } 30 \text { practice trials, with } 10 \text { seconds between } \\
\text { each trial conducted. }\end{array}$ \\
\hline Ulrich et al., 2014 & RCT & $\begin{array}{l}\text { Measurements were obtained in the month before the intervention (pre-intervention), } \\
\text { at } 7 \text { weeks after the intervention, and at } 12 \text { months after the pre-intervention } \\
\text { measurement for all participants. }\end{array}$ \\
\hline Chiviacowsky et al., 2013 & $\mathrm{RI}$ & The study was conducted over 48 hours. \\
\hline Ringenbach et al., 2012 & $\mathrm{RI}$ & Total testing time was between 40 and $70 \mathrm{~min}$. \\
\hline Courbois et al., 2013 & $\mathrm{RI}$ & One session of approximately $30 \mathrm{~min}$. \\
\hline
\end{tabular}


Table 2. Studies analysing motor learning and Down syndrome.

\begin{tabular}{c|c|c}
$\begin{array}{c}\text { Study } \\
\text { reference }\end{array}$ & Participants & $\begin{array}{c}\text { Outline of experimental methodology } \\
\text { relevant to this review }\end{array}$
\end{tabular}

Bussy et al., 14 patients with Fragile X syndrome, Implicit learning is variable in genetic syndromes and therefore relatively 2011

12 with Down syndrome and 12 independent of general intellectual capacities.

typically developing children.

Chiviacowsky Thirty adults. All diagnosed with DS et al., 2012 and mild intellectual disability (IQ range: $50-70)$

Ulrich et al., The participants were children who 2014 were 8 to 15 years of age and who had been diagnosed with DS.

Chiviacowsky 20 adults with DS. et al., 2013

Ringenbach 20 chronological age-matched et al., 2012 (CA), and 20 mental age-matched (MA).
Learning was assessed by a retention test, consisting of 10 trials without feedback, one day later. The self-control group demonstrated more effective learning of the task than the yoked group.

The results indicated no group differences at the pre-intervention session. Analysis showed that participants who learned to ride spent significantly less time in sedentary activity at 12 months after the preintervention measurement and more time in moderate to vigorous physical activity than participants in the control group.

The results of this study showed that participants with DS achieved similar learning both on a throwing task with reduced frequency to $33 \%$ of knowledge of results (KR) as a task with a frequency of $100 \%$ of $K R$. These results confirm previous studies on the subject by showing that reduced frequencies can be as beneficial or superior to the learning of motor skills as increased frequencies.

The results suggest that visual instruction provides the best information for people with DS to aid in performance of many different types of movements.

Table 3. Studies analysing virtual reality and Down syndrome.

\begin{tabular}{|c|c|c|}
\hline $\begin{array}{l}\text { Study } \\
\text { reference }\end{array}$ & Participants & Outline of experimental methodology relevant to this review \\
\hline $\begin{array}{l}\text { Wuang et al., } \\
2011\end{array}$ & $\begin{array}{l}105 \text { children } \\
\text { plus another } \\
50 \text { as controls. }\end{array}$ & $\begin{array}{l}\text { The results suggest that virtual reality using Wii gaming technology demonstrates benefit in } \\
\text { improving sensorimotor functions among children with DS. }\end{array}$ \\
\hline $\begin{array}{l}\text { Courbois et } \\
\text { al., } 2013\end{array}$ & $\begin{array}{l}\text { DS }(\mathrm{N}=10) \\
\text { and control } \\
\text { participants. }\end{array}$ & $\begin{array}{l}\text { The results showed that most of the participants with DS were able to learn routes through } \\
\text { the Virtual environment, even though they needed more trials than the chonologicalage } \\
\text { controls to reach the learning criterion. However, they did not show flexible wayfinding } \\
\text { behaviour because they were unable to find a shortcut between two known locations }\end{array}$ \\
\hline
\end{tabular}

Table 4. Main Consideration.

\begin{tabular}{|c|c|c|}
\hline Articles & Main consideration & $\begin{array}{l}\text { PEDro } \\
\text { Score }\end{array}$ \\
\hline $\begin{array}{l}\text { Wuanget al., } \\
2011\end{array}$ & $\begin{array}{l}\text { Participants in the VR Wii group had a greater pre-post change in motor proficiency, visual- } \\
\text { integrative abilities, and sensory integrative functioning. Virtual reality using Wii gaming } \\
\text { technology demonstrated benefit in improving sensorimotor functions among children with DS. }\end{array}$ & $6 / 10$ \\
\hline $\begin{array}{l}\text { Bussy et al., } \\
2011\end{array}$ & $\begin{array}{l}\text { Implicit learning is variable in genetic syndromes. It is relatively efficient in at least a subgroup of } \\
\text { Fragile X patients, impaired in Williams syndrome, and preserved with a sensitivity to interference } \\
\text { in Down syndrome. }\end{array}$ & $5 / 10$ \\
\hline
\end{tabular}


Chiviacowsky The objective was to verify the effects of two frequencies (100 and 33\%) of knowledge of

et al., 2012 results (KR) on the learning of a motor skill, in individuals with Down syndrome (DS). The authors concluded that reduced relative frequencies of $K R$ are as effective as high frequencies in the learning of simple motor tasks in adults with DS.

Ulrich et al., Learning to ride can reduce time spent in sedentary activity and increase time spent in moderate

2014 to vigorous physical activity, which may influence the health and functioning of these children.

Chiviacowsky Participants with Down syndrome practiced a linear positioning task. In the self-control group, et al., 2013 learners were provided with feedback about the movement outcome at their request. The selfcontrol group demonstrated more effective learning of the task than the yoked group. Selfcontrolled feedback enhanced motor learning in participants with Down syndrome.

Ringenbach The results suggest that visual instruction provides the best information for people with DS to aid in performance of many different types of movements.

Courbois

The aim of this study was to assess wayfinding abilities in individuals with Down syndrome (DS). The results suggest that most individuals with DS can acquire knowledge about specific routes, but are unable to integrate that knowledge into a configurational understanding of the environment.

\section{Discussion}

Individuals with Down syndrome (DS) have different types of physical disabilities and delays in motor performance in the first months of life compared with children who are developing normally [3, 20]. However, the appearance of these disabilities and delays is influenced by the living environment and the stimulation the children receive [21]. Among people with Down syndrome there is also a wide variation in mental abilities and developmental progress, that is, people with Down syndrome also differ from each other [1].

When deciding to conduct a systematic review, we were aware of the importance of determining the methodological quality of each study included in our review. Based on the PEDro scale [22], three of the selected studies were grade 6 , equivalent to "good" according to criteria adopted by Snider, Majnemer and Darsaklis [17], three were grade 5 and one was grade 4, equivalent to "fair" [17].

All studies included in this review were randomized, but the importance of or method of randomization need not be explicit. Procedures such as data entry or coin toss should be considered as a form of randomization. Quasi-randomization of procedures such as those based on the hospital record number, date of birth, or alternation, do not satisfy this criterion of randomization. Random assignment ensures that treatment and control groups are comparable (within the limits of "random" events) [22].

The seven studies contained different participants and sample sizes. The largest population was in Wuang et al. [23], who had 105 patients in their sample, and the smallest population was in Courbois et al. [24], who only analysed 10 individuals with DS. Both these studies investigated the use of $V R$, and had the same PEDro score. Studies analysing individuals with DS and motor learning examined an average of 20 individuals, so the results may have been easier to analyse. We assume that this difference may be due to insertion work using the VR technology is new, and these studies are just beginning.

Among the studies that analysed motor learning, Ringenbach et al. [11] attempted to unders- 
tand how persons with (DS) perform different tasks and to assess whether there were any differences in performance based on the type of instructions. They found that individuals with DS performed more efficient movements with smaller amplitudes, and followed visual instructions better than auditory and verbal instructions for all types of tasks whereas chronological age-matched performed similarly with all instructions and mental age-matched performed with smaller amplitudes with visual instructions than auditory instructions. These results suggest that visual instruction provides the best information for people with DS to aid in performance of many different types of movements.

Another major difference in the movements performed by persons with Down syndrome is the different patterns of muscle activation they use to perform and adjust these movements to changes in the environment [25]. According to Gardiner et al. [26], deficits in learning, memory, and language in DS lead to general cognitive impairment, which is typically in the mild-to-moderate range.

However recent studies show that persons with DS are able to adaptively modulate muscle activity, producing rapid bursts to contrast sudden variations joint or restore basic muscle hypotonia During relaxed limb oscillations [27]

For as Shields et al [28] mentions in his study the physical inactivity that report the delay in acquisition, fouled representing a decrease in the development of functional skills, also Affects social interaction, since DS individuals' movement is not standard and is considered thus atypical. Time synchronization is a very important factor in the acquisition and performance of motor skills that generate the need to adapt the actions of body segments to external events of the environment that are changing their position in space. This results were reported by Torriani- Pasin et al. [29], who found through a coincident timing task that individuals with DS typically present impairments in timing, which were reflected in slower and delayed responses.

Some studies have shown that knowledge of results (KR) when manipulated self-controlled manner directly influences individual learning [30], however Ferreira et al. [31] analysed three different strategies to provide $K R$, and noted that there was no effect of self-controlled frequencies for motor learning when using the random practice.

Likewise Chiviacowisky et al. [8] found that the frequency of knowledge of results $(K R)$ did not influence the learning of motor skills in patients with Down syndrome. In their study a group of individuals with DS received $100 \%$ of the KR and another $33 \%$ both in the acquisition phase and after a 48-hour retention phase during which KR was not supplied; the results showed no difference between groups.

Tertuliano et al. [32] highlighted their analysis to the transfer in individuals with normal development. They provided a KR of $50 \%$ and 33\% for each group in the acquisition phase but no $K R$ in the transfer phase, and found the best performance in the 33\% acquisition phase and the transfer phase. They concluded that the lower frequency of feedback helped improve performance.

Chiviacowsky et al. [6] examined whether the learning benefits of an external focus of attention (i.e., on the movement effect) relative to an internal focus (i.e. on the movement), as found previously in non-disabled children and adults, would also be found in children with intellectual disabilities (ID). The practice phase consisted of 40 trials, and attentional focus reminders were given after every third trial. Learning was assessed 1 day later by retention and transfer (greater target distance) tests, each consisting of 10 trials. No focus reminders were given on that day. The external focus group demonstrated more effective learning than the internal focus group, as shown by more accurate tosses on the transfer test. Their findings showed 
that instructions that induce an external focus of attention can enhance motor learning in children with IDs [6]. However, a later study by the same authors [8] did not corroborate these findings. After practicing a linear positioning task in the retention phase comprising 10 trials without feedback, learners in the self-control group were provided with feedback about the movement outcome at their request one day later in the acquisition phase. Each participant in the yoked group received the same feedback schedule as their counterpart in the self-control group. However, the self-control group demonstrated more effective learning of the task than the yoked group. The authors thus concluded that there is a need for self-controlled feedback-enhanced motor learning in participants with Down syndrome.

According to Dubey et al. [33] the success of rehabilitation resides in three key concepts: feedback, repetition and motivation. Based on this concept Barzilay and Wolf [34] proposed a novel approach to neuromotor training by combining the advantages of a virtual reality platform with biofeedback information on the training subject from biometric equipment and with the computational power of artificial neural networks. For rehabilitation, the simulated experience may be designed to address certain aspects of sensory or motor loss experienced by an individual [13].

Virtual reality (VR) is an emerging technology with a variety of potential benefits for many aspects of rehabilitation assessment, treatment, and research through its capacity to allow the creation and control of dynamic 3-dimensional, ecologicaIly valid stimulus environments within which behavioural responses can be recorded and measured. Barzilay and Wolf [34] claim that VR systems can teach and correct a subject during practice with real time feedback and, as a result, can significantly improve the accuracy of their performance.

The aim of a study by Courbois et al. [24] was to assess wayfinding abilities in individuals with
Down syndrome (DS). The ability to learn routes though a virtual environment (VE) and to make a novel shortcut between two locations was assessed in individuals with DS and control participants. The results showed that most of the participants with DS were able to learn routes through the $V E$, even though they needed more trials than the controls to reach the learning criterion [24]. However, they did not show flexible wayfinding behaviour because they were unable to find a shortcut between two known locations (unlike the controls). The results suggest that most individuals with DS can acquire knowledge about specific routes, but are unable to integrate that knowledge into a configurational understanding of the environment [24].

VR has the potential to offer experiences that are engaging and rewarding. In VR, the focus is shifted from the individual's efforts in producing a movement or completing a task to that of interaction with the virtual environment [13]. Wuang et al. [23] investigated the effects of a strength and agility training programme in adolescents with Down syndrome through an exercise training programme that consisted of treadmill exercise and virtual-reality-based activity, and found that short-term exercise training is capable of improving muscle strength and agility in adolescents with DS.

Games using VR have contributed to the development and learning of children with Down syndrome as can be observed in the study by Wuang et al. [23]. These authors reported that the use of a Wii game in the intervention led to an improvement in sensorimotor functions in children with DS by means of repetitive intensive training and the observation, practice, and representation on the screen of task-specific activities. They compared the effect of standard occupational therapy (SOT) and virtual reality using Wii gaming technology (VR Wii) on children with Down syndrome (DS). One hundred and five children were randomly assigned to intervention with either 
SOT or VR Wii, while another 50 served as controls. All children were assessed with measures of sensorimotor functions. At post-intervention, the treatment groups significantly outperformed the control group on all measures.

Berg et al. [27] found that the use of Wii games four times each week for 20 minutes each session for 8 weeks in a child with DS was accompanied by improvements in upper-limb coordination, manual dexterity, balance, postural stability, and limits of stability control.

Virtual reality interventions have been shown to improve cognitive function and concentration through an individual's interaction with a pleasant activity. Importantly, the enjoyment experienced while working with VR may increase the level of participation. In addition to generating realistic situations for testing, intervention and collection of data, the provision of immediate and positive feedback through VR has been shown to increase selfesteem and empowerment [13].

It was also found that these experiences implemented primarily with a view to promoting health, highlighting elements such as autonomy, empowerment and decision-making [35]. This findings might be valuable to the health care of intellectual diseases, such as Down Syndrome.

Health care is conventionally regarded as the diagnosis, treatment, and prevention of disease, illness, injury, and other physical and mental impairments in humans.

How we define the quality of public health at any given time must be compatible with future generations enjoying health in an equivalent way [36]. Public health practitioners must also integrate sustain ability in the definition of public health.

\section{Conclusion}

The motor learning in individuals with Down syndrome can occur following different tasks, allowing better motor control and specific skills often independently of the result of knowledge, and is more effective in the presence of visual feedback and self-control. Individuals with Down syndrome respond positively and effectively, improving their sensory motor control, when stimulated with different and complementary tasks to conventional therapy, especially therapy involving virtual reality, are able to perform the pre-set task, but are not able to trace routes with different alternatives.

\section{Authors' Contributions}

All authors participated in the acquisition of data and revision of the manuscript. All authors determined the design, interpreted the data and drafted the manuscript. All authors read and gave final approval for the version submitted for publication.

\section{Declaration of Interest}

The authors report no conflict of interest. All authors were responsible for the content and writing of this paper.

\section{Acknowledgments}

Authors would like to thank to CAPES (Higher Education Personnel Training Coordination). 


\section{References}

1. E.Lana-Elola, S.D. Watson-Scales, E.M. Fisher, V.L. Tybulewicz, Down syndrome: searching for the genetic culprits, Dis Model Mech, 4 (2011) 586-595.

2. B.L. Handena, A.D. Cohena, U. Channamalappaa, P. Bulovab, S.A. Cannonc, W.I. Cohenc, C. A. Mathisd, J.C. Priced, W.E. Klunka, Imaging brain amyloid in nondemented young adults with Down syndrome using Pittsburgh compound B, Alzheimer's \& Dementia, 8 (2012) 496-501.

3. R.L. Carvalho, D. A. Vasconcelos, Motor Behavior in Down Syndrome: Atypical Sensoriomotor Control. S. Dey (Ed.), Prenatal diagnosis and screening for Down syndrome, In Tech Publishers,(2011) 34-42.

4. R.J. Palisano, S.D. Walter, D.J. Russell, P.L. Rosenbaum, M. Gemus, B.E. Galuppi, L. Cunningham, Gross motor function of children with down syndrome: creation of motor growth curves, Arch Phys Med Rehabil, 82 (2001) 494-500.

5. I.T. Lott, M. Dierssen, Cognitive deficits and associated neurological complications in individuals with Down's syndrome, Lancet Neurol, 9 (2010) 623-633.

6. S. Chiviacowsky, C. Machado, A.C. Marques, J.F.G. Schild, R. Drews, Motor learning and Down syndrome: effects of reduced relative frequency of knowledge of results, Revista Brasileira de Cineantropometria \& Desempenho Humano, 15 (2013) 225-232.

7. E. Maas, D.A. Robin, S.N.A. Hula, S.E. Freedman, G. Wulf, K.J. Ballard, R.A. Schmidt, Principles of Motor Learning in Treatment of Motor Speech Disorders, American Journal of SpeechLanguage Pathology, 17 (2008) 277-298.

8. S. Chiviacowsky, G. Wulf, C. Machado, N. Rydberg, Selfcontrolled feedback enhances learning in adults with Down syndrome, Brazilian Journal of Physical Therapy, 16 (2012) 191196.

9. G. Bussy, E. Charrin, A. Brun, A. Curie, V. des Portes, Implicit procedural learning in fragile $X$ and Down syndrome, J Intellect Disabil Res, 55 (2011) 521-528.

10. W.F. Possebom, T.D.d. Silva, A.H.N. Ré, T. Massetti, L.Z. Belisário, E. Ulian, Z. Graciani, C.B.d.M. Monteiro, Aprendizagem motora em pessoas com síndrome de Down: tarefa de labirinto no computador, (2013) 54-60.

11. S.D. Ringenbach, G.M. Mulvey, C.C. Chen, M.L. Jung, Unimanual and bimanual continuous movements benefit from visual instructions in persons with Down syndrome, J Mot Behav, 44 (2012) 233-239.

12. S.V. Adamovich, G.G. Fluet, E. Tunik, A.S. Merians, Sensorimotor training in virtual reality: a review, NeuroRehabilitation, 25 (2009) 29-44.

13. H. Sveistrup, Motor rehabilitation using virtual reality, J Neuroeng Rehabil, 1 (2004) 10.
14. C.L.F. Chan, E. K.Y. Ngai, P.K.H Leug, S. Wong, Effect of the adaped virtual realitycognitive training program among Chinese olderadults with chonic schizophrenia: a pilot study, Int J Geriatr Psychiatry, 6 (2009) 547-655.

15. D.L. Damiano, S.L. DeJong, A systematic review of the effectiveness of treadmill training and body weight support in pediatric rehabilitation, J Neurol Phys Ther, 33 (2009) 27-44.

16. T.D. Parsons, A.A. Rizzo, S. Rogers, P. York, Virtual reality in paediatric rehabilitation: a review, Dev Neurorehabil, 12 (2009) 224-238

17. L. Snider, A. Majnemer, V. Darsaklis, Virtual reality as a therapeutic modality for children with cerebral palsy, Dev Neurorehabil, 13 (2010) 120-128.

18. R.F. Sampaio, M.C. Mancini, Estudos de revisão sistemática: um guia para síntese criteriosa da evidência científica, Braz. J. Phys. Ther.(Impr.),11 (2007) 83-89.

19. D.C. Bland, C. Zampieri-Gallagher, D.L. Damiano, Effectiveness of physical therapy for improving gait and balance in ambulatory individuals with traumatic brain injury: a systematic review of the literature, Brain Inj. 25(2011) 664-679.

20. L.J. Hahn, D.J. Fidler, S.L. Hepburn, S. Rogers, Early Intersubjective Skills and the Understanding of Intentionality in Young Children with Down Syndrome, Res Dev Disabil 34 (2013) 4455-4465.

21. T.D. Sanger, M.R. Delgado, D. Gaebler-Spira, M. Hallett, J.W. Mink, Classification and definition of disorders causing hypertonia in childhood, Pediatrics, 111 (2003) 89-97.

22. D. Beaton, C. Bombardier, F. Guillemin, M.B. Ferraz, Recommendations for the cross-cultural adaptation of the DASH \& QuickDASH outcome measures, Institute for Work \& Health, 1 (2007) 1-45.

23. Y.P. Wuang, C.S. Chiang, C.Y. Su, C.C. Wang, Effectiveness of virtual reality using Wii gaming technology in children with Down syndrome, Res Dev Disabil, 32 (2011) 312-321.

24. Y. Courbois, E.K. Farran, A. Lemahieu, M. Blades, H. MengueTopio, P. Sockeel, Wayfinding behaviour in Down syndrome: a study with virtual environments, Res Dev Disabil, 34 (2013) 1825-1831.

25. M.L. Latash, Learning motor synergies by persons with Down syndrome, J Intellect Disabil Res, 51 (2007) 962-971.

26. K. Gardiner, Y. Herault, I.T. Lott, S.E. Antonarakis, R.H. Reeves, M. Dierssen, Down syndrome: from understanding the neurobiology to therapy, J Neurosci, 30 (2010) 14943-14945.

27. P. Berg, T. Becker, A. Martian, K.D. Primrose, J. Wingen, Motor control outcomes following Nintendo Wii use by a child with Down syndrome, Pediatr Phys Ther, 24 (2012) 78-84.

28. N. Shields, K.J. Dodd, C. Abblitt, Children With Down Syndrome Perform Sufficient Physical Activity to Maintain Good Health? A Pilot Study, Adapted Physical Activity Quarterly, 26 ( 2009) 307320. 
29. C. Torriani-Pasin, G.M. Bonuzzi, M.A. Soares, G.L. Antunes, G.C. Palma, C.B. Monteiro, L.C. de Abreu, V.E. Valenti, A.P. Junior, R. Wajnsztejn, U.C. Correa, Performance of Down syndrome subjects during a coincident timing task, Int Arch Med, 6 (2013) 6-15.

30. A. Ali, B. Fawver, J. K, J. Fairbrother,C.M. Janelle, Too much of a good thing: random practice scheduling and self-control of feedback lead to unique but not additive learning benefits, Frontiers in Psychology | Movement Science and Sport Psychology 3 (2012) 3-503.

31. G.M. Ferreira, M.R. Albuquerque, N.F.A. Ambrósio, A.T. Bruzi, L.R. Palhares, Efeitos do conhecimento de resultados autocontrolado na aprendizagem motora. Motriz, 18 (2012) 495-504.

32. I.W. Tertuliano, O.P. de Souza Júnior, A.S. da Silva Filho, U.C. Corrêa, Estrutura de prática e freqüência de" feedback" extrínseco na aprendizagem de habilidades motoras, Revista Brasileira de Educação Física e Esporte, 22 (2008) 103-118.

33. A.K. Roy, Y. Soni, S. Dubey, Enhancing effectiveness of motor rehabilitation using kinect motion sensing technology. Global Humanitarian Technology Conference, (2013) 298 - 304.

34. O. Barzilay, A. Wolf, Adaptive rehabilitation games, J Electromyogr Kinesiol, 23 (2013) 182-189.

34. O. Barzilay, A. Wolf, Adaptive rehabilitation games, J Electromyogr Kinesiol, 23 (2013) 182-189

35. Bezerra IMP, et al. Professional activity in the context of health education: a systematic review. 24(3): 255-262. Doi: dx.doi. org/10.7322/jhdg.88909

36. Atrash HK, Carpentier R. The evolving role of public health in the delivery of health care. Journal of Human Growth and Development, 2012; 22(3): 396-399.

\section{Comment on this article:}

\section{(f) $(8)$ in $8+\mathbf{S} P$}

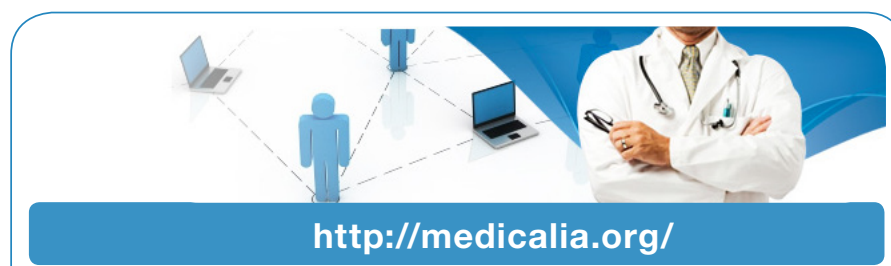

Where Doctors exchange clinical experiences, review their cases and share clinical knowledge. You can also access lots of medical publications for free. Join Now!

\section{Publish with iMedPub}

http://www.imed.pub

International Archives of Medicine is an open access journal publishing articles encompassing all aspects of medical science and clinical practice. IAM is considered a megajournal with independent sections on all areas of medicine. IAM is a really international journal with authors and board members from all around the world. The journal is widely indexed and classified Q1 in category Medicine. 